\title{
The Planning Policy of Bilingualism in Education in Iraq
}

\author{
Bilal Huri Yaseen (Corresponding author) \\ Al-Anbar Directorate of Education \\ Ministry of Education, Iraq \\ E-mail: byaseen2010@gmail.com \\ Hani Shakir \\ Al-Anbar Directorate of Education \\ Ministry of Education, Iraq \\ E-mail: hanishakir.ird@gmail.com \\ YM Hajah Tenku Mazuwana Bt. T. Mansor \\ Faculty of Modern Languages and Communication, University Putra Malaysia, Malaysia \\ E-mail: wana@upm.edu.my
}

Received: 06-11-2015

Published: 01-05-2016
Accepted: 25-01-2016

doi:10.7575/aiac.ijalel.v.5n.3p.1
Advance Access Published: March 2016

URL: http://dx.doi.org/10.7575/aiac.ijalel.v.5n.3p.1

\begin{abstract}
Iraq as a multicultural and multilingual country has different languages as Arabic, which is the dominant language, and it also has some other minority languages, such as Kurdish, Turkish, Syriac....etc. Over the last 80 years, Iraq which was involved in some political struggles, had faced many internal problems regarding the Arabic domination that occurred, and this was owing to the absence of clear language policy used. Children learning in the Iraqi system, for instance, speak and study all courses in Arabic, while speaking and using their own culture at home tend to be done in their first language. The minorities' language usage in Iraq was ignored both inside the schools as well as in the curriculum construction. So this study focuses on the following issues: the first issue is, What is the strategy of language planning policy in Iraq? the study discusses the strategy and the planning educational system that Iraq applies now, the second issue is, What is the status of minority languages in Iraq? Iraq is a multicultural county and has many minorities communities with different languages, the third issue is, What are the challenges of language in Iraq? as long as there is different languages within one country the study also focuses on the challenges that been faced in the planning policy system, and the last issue is, Is there a homogenous relationship during the current policy? How? the study shows the homogenous relationship inside the current policy and the researches give many suggestions and recommendations regarding to the current policy and what is needed for improving the educational planning policy system.
\end{abstract}

Keywords: Planning Policy, Bilingualism, Education, Culture, Harmony, Language Shift

\section{Introduction}

It has been estimated through various estimations throughout the world that two out of three people all over the world are either multilingual or bilingual; or in other words, over half of the world population regularly use at least two languages in their daily communication

This new century comes together with social facts like Multiculturalism and Multilingualism evident in most school classes and play fields. The interpretation of 'bilingualism' comes in different ways; for some, it highlights an opportunity to have the ability to communicate in two languages as with Bloomfield (1933, cited in Mackey, 2000), Macnamara (1967) and Weir (2000). For others, it simply suggests the ability to communicate in two languages, but with higher skills in one language as with Titone (1972, cited in the Harmers \& Blank, 2004), states that Bilingualism serves as the capacity of an individual to speak a second language based on its structures and patterns, without any pragmatic transfer from the first language.

Iraq as a multicultural and multilingual country has different languages as Arabic, which is the dominant language, and it also has some other minority languages, such as Kurdish, Turkish, Syriac....etc. Over the last 80 years, Iraq which was involved in some political struggles, had faced many internal problems regarding the Arabic domination that occurred, and this was owing to the absence of clear language policy used.

After the invasion by the Americans and the coalition forces of Iraq in 2003, a new era had begun, in which many international companies, NGOs. (Non-Governmental Organizations), and the emergence of oil and gas investors were established in the country to urge the government of Iraq to think seriously about many matters that had curbed the development of the new era. Thus, due to the lack of clear policy, there were some internal and external needs to use the multilingual system such as adding English and Kurdish languages in the economic, commercial, education system, universities, communication, to name a few. In relation to these needs and others from the Iraqi society to look after the 
minority languages in the new Iraqi educational system, the government had no other choice but to respond to the demands of the various parties.

Children learning in the Iraqi system, for instance, speak and study all courses in Arabic, while speaking and using their own culture at home tend to be done in their first language. In consequence, many children did not receive any education in their mother tongue; the over whelming numbers of students were members of the linguistic minority or an ethnic, while Arabic as language and culture conquered the school. Then necessary need for the people of Iraq and especially students is to keep abreast with the globalization and the increasing development to trade and all other economic problems. A lot of English institutes motivated the Iraqi government to change its education system policy and move towards internationalism and globalization. The higher committee of Education in Iraq had posed a law to the Iraqi parliament on 2005 which asks to make Iraq as bilingual in its education system and to permit the schools to adopt curriculum in English language to be provided and taught to all students and as well as to use Kurdish as substitute language instead of Arabic in their regions of Kurd's majority. Actually, this created as at is faction to the parent so the students who may create a jump in the Iraqi educational system. Regarding English , most of the parents are sending their children to private languages institutes in order to give a chance to their children to acquire and learn the English language as is an added value tothe students' qualifications.

The mentioned is embedded in the new development that Iraq recently witnessed in all fields as education, trade, human resources, industries and companies and non-governmental organizations; which altogether gave the motive to the government to find feasible policies that serve and lead Iraqis toward upholding internationalism.

\section{The Study Questions}

1. What is the strategy of language planning policy in Iraq?

2. What is the status of minority languages in Iraq?

3. What are the challenges of language in Iraq?

4. Is there a homogenous relationship during the current policy? How?

\section{Statement of the Problem}

Curriculum planners have identified bilingualism between both the home and school in Iraq as a problem, where it does not lead to balanced chance of language usage that may impose harmful troubles in the society, and also, it poses serious challenges for the Iraqi educational system.

The educational planning system in Iraq has had to brave a number of difficulties and challenges in the last two decades, which negatively dented its efficacy. The main difficulty lies in the fact that there was legislation, but it did not have clear execution; instructions or implementations plan because there was either no real interest to implement or due to political problems like quotas and benefits of political parties and which may be used as a tool of political pressure. In effect, Arabic is still the dominant language in the educational system in Iraq, whereas the minorities like, Kurdish and Turkish were under the illusion that their language is formal in schools like the Arabic. This opinion had led to a problem in the use of the educational system in the schools.

The minorities' language usage in Iraq was ignored both inside the schools as well as in the curriculum construction. They (minorities) were not given any choice to learn their mother tongue language outside homes, and just headed to learn the dominant language, which was the formal language "Arabic." However, other minorities still suffered in Kirkuk, Ninawa and some parts of Diyala where Arabic is the only language that was allowed to be taught, while there was an exception of Kurdistan Region schools (the north of Iraq) following the independence of this region from the central ruling of Iraq.

This study characterized the linguistic diversity status in addition to the minority languages inside Iraq covering four stages:

1- 1925-1958: In this first stage, the Iraqi constitution, draws the basis of the language diversity, and it dwelt into the freedom of learning and using different languages in education with some hesitation to find the solutions to the problem, especially through the legislations and declaration of 1932. The constitutions guaranteed the right of citizens of to get free education (Al-Hirmizi -2003). Unfortunately, all these hopeful legislations did not have a clear public policy.

2- 1958-1970: In this stage, there was what is regarded as the 'dark period' due to the high ignorance for the minor groups' languages and all other linguistics' diversity in spite of different versions of the constitution and legislations issued during that stage of history.

3- 1970- 2003: There was a series of political attempts in order to create the feeling of anger of the ethnic minorities towards the Iraqi government; for this reason, the government had to find and modify some articles in the constitution. In effect, there are some laws legislated to guarantee the linguistic diversity in addition to the languages of minority ethnic group as well. Unfortunately, they were far from realistic; instead it was used to suppress the minorities without offering any real solution or policy for this problem.

4- 2003- until now: The constitution included many articles concerning the language of minority ethnic groups and the linguistic diversity with good public policy that had placed Iraq back on track; however, the implementation of these policies and legislation was delayed, as a result of the fight against terrorism and poor financial allocations. 
The development and the status change according to these four stages came about, as the people really need peaceful co-existence, and the increased sense of responsibility as citizens, and promote unity and solidarity between the multicultural groups. Hence, the study lays an emphasis on the significance of this issue from different sides taking into account the aspects of national unity, sociocultural, economic, human rights and the danger of repeated remissness of this issue.

\section{Current Language Policy}

The Iraqi constitution in its approved law in January 7, 2014 considers Arabic and Kurdish as the two official languages of Iraq. In addition, it ensures the right of all Iraqis to educate their children in their mother tongues. This can be materialized via public educational institutions or in private schools (Iraqi constitution 2014, Articles3, 4 and 7). The constitution establishes specifically what official languages mean and how this policy is to be carried out. Firstly, the official gazette will be bilingual, Arabic and Kurdish. All speech and official documents in government organizations such as the Council of Parliament will be in one of the two languages. Moreover, it allows the opening of schools for all stages of teaching in Arabic or Kurdish or Turkmen or Syriac, or Armenian or Mandaean in government educational institutions, or any other languages in private educational institutions in lieu with educational guidelines. Bank notes, passports and stamps as formal documents will also be bilingual (Iraqi constitution2014, Articles 4, 7 and 8).

Article 9: Turkmen language and Syriac language have two official languages in the administrative units that constitute the Turkmen or Syriac as part of the population.

Article 10:Each region or province has the right to take any other local language as additional official language if most of the population give their approval through the referendum.

Article 11: Finding a higher committee to adhere to the implementation of this law; and it would be attached to the Council of Ministers, chaired by a representative of the General Secretariat of the Council of Ministers, the membership of a representative of the Kurdistan Regional Government, a representative of the Office of the Chamber of Deputies, assisted by a team of linguists, academics and representatives of the Turkmen and Assyrians and Mandeans and also added, a representative of any other Iraqi languages.

Article 12: The tasks and quorum of the Committee stipulated in Article 12 of this Law follow instructions thathave been released by the Prime Minister.

Article -13-: This law aims to:

- Firstly, guarantee Constitutional respect, other than activate and organize the use of the Republic of Iraq's official languages.

- Secondly, raise and spread the linguistic awareness, towards unifying the components of Iraq and a better instillation and consolidation of both humanitarian and national concepts.

- $\quad$ Thirdly, achieve the spirit of pride in using their mother tongue.

- Fourth, to make sure that there are equality and balance between Arab and Kurdish's rights and privileges to enable them to be used in federal institutions.

- $\quad$ Fifth, offer support and develop Arabic and Kurdish languages and other languages namely Turkmen, Syriac and Armenian, Mandaean.

Article -14-

- Firstly, every Iraqi citizen or foreign citizen is entitled to teach his/her children their respective mother tongue.

- Secondly, every Iraqi ethnicity has the right to establish colleges or institutes and cultural centers or scientific synagogues which uphold the development of language, as well as both culture and heritage.

Article -15-: The Iraqi Academy of Sciences and the Kurdish Academy are the only reference for the interpretation of terms and words, should there be any misunderstanding.

Article -16-: Anyone who violates the provisions of this law will be dealt with as follows:

- First, impose disciplinary sanctions against him/her if he/she happened to be an official employee.

- Second, warning the unofficial employee to remove the violation in the duration of 15 days, and when he refused to be punishable by a fine of not less than (50) fifty thousand dinars for each day the removal of the violation will be deemed failed.

- Third, for each affected, reinstate the right to move criminal claims when the provisions of this law are violated.

Article -17- The Council of Ministers has to release the set of instructions to facilitate the implementation of the law provisions.

Article -18- This law shall be published in the Official Gazette and implemented after ninety (90) days from the publication date.

\section{Reasons}

This law is approved according to the Article (4) of the Constitution, which lays an emphasis on respect towards all the national diversity and language in Iraq. The law was firm on the consolidation of the human dimension and the harmony with the Islamic teachings, which stress on respect for all languages, and to enable the basic components of the Republic of Iraq to have a free expression of its need and requirements in their original languages. 


\section{Socio-Cultural Effect}

The development and spread of the ethnic languages were done by schools, and it was not allowed to open new schools or cultural institutes by the minorities until January 2014. All similar schools that previously opened were under close monitoring of the government; hence, the Kurds, Turkmen and other minor groups were in obligation to study in Arabic. For instance, during the period of Ba'ath party, which was in 1968-2003, Turkmen had had to succumb to the darkest era of their history. They had to address the requests from the government through signed petitions to close all schools teaching the Turkish in Kirkuk and administrating their areas by Arab employees. (Mofaq Kerkuklu, 2007).

One can imagine the weakness and the untruthful desire of the Iraqi education system towards the ethnic minority regions before 2003. To spark controversy, in the USA, the government provides some concentrated programs for families and children as EHS (Early Head Start); these aim to consolidate children's willingness and desire to learn their ethnic language. As the families are culturally and linguistically varied their children required literacy experiences in multifarious ways. Children under five years might have already been exposed to their mother tongue and their ethnic culture, which is the mother language used in their homes and communities. If the reason is down to exposure, subsequent children aged 1-3 years can easily work on their first language, which is the non-English language(Centre, E. H. 2001).

The minority languages or ethnic languages are not adequately cared for, like the other countries; for instance, in China, The National Commission for Minorities (NCM) is the main government committee, responsible for all planning strategies of linguistic minority languages in China, and it aims to keep these languages autonomous. (Huang Xing, 2003)

The minority had given some bad reactions to this kind of injustice, and this reflects their behaviour towards the other people and their culture. Obviously, it also reflects on the social status, especially in the marriages of Kurds, Turkman, Assyrian...etc. and the Arabs in Iraq. (Kerkuklu, M. S. 2009).

Without a doubt, the essential ways of communication with others lie in the language. Learning languages, even under very experienced teachers, is usually placed under long-term programs. It establishes the different ways of looking out into the world as well as the human communication. It is also worthy of note that learning languages is one the most rewarding intellectual activities imaginable. (Willems, 2002)

At the end, according to(Curran, 2003), people need to establish a great sense of relations between their communities and further confirm and glorify their linguistic diversity.

\section{Implications for Language Planning}

"Language planning refers to deliberate efforts to influence the behaviour of others with respect to the acquisition, structural, or functional allocation of their language codes" (Cooper, 1989: 45). The initial implications of this study rest on the status and the acquisition of English in Iraq's educational system. The study results have shown the worthy linguistic, cultural, political and educational aspects with regard to the profile of English in Iraq. Schools and highereducation institutions are the basic frameworks in which languages are studied in a systematic way and which ensure maintenance and vitality. Allowing diverse attitudes and receptiveness to a language policy can also motivate English learning.

Prator (in Cooper, 1989: 31) has this to say: "language policy making involves decisions about the teaching and use of language, and their careful formulation of those empowered to do so, for the guidance of others." Thus, planning for English involves both the planning acquisition and its status. It is seemingly apparent that there is an urgent need for a strategic plan for a language policy of English principally spurred by ideological and political considerations. The low linguistic capital value of English in Iraq deemed unable to draw stronger social elements is due to the perceived low instrumentality of the language and its linkage to supposed hostile elements. Malice to its speakers must not evoke a sense of hatred to the language learning. A strategic plan for English sees that the macro goals of learning English and the weak recognition of the consumers (users) are arranged. At the national level, a rise in the demand for English would inexorably raise its linguistic major value. From the sociological viewpoint, the promotion of English in Iraq is fundamentally a function of several factors: national necessity, scientific education media, ideological and political considerations. A strategic plan must stress on implementing the motivation for the betterment of English learning.

The acquisition of English as a strategic plan should then be started. It must be introduced with a set of definitions, parameters and positions, concluded after extensive studies, establishing a vision of the status of English and how it will be in Iraq. A strategic plan for English then might be called strategic preparation, because it constitutes a preparation for successful treatment of future linguistic and extra linguistic challenges and opportunities. Hence, a strategic plan of Bilingualism for English in Iraq.

\section{Language Maintenance and Shift}

Language maintenance and shift, as qualified by (Joshua Fishman, 1968) encompass the stability or set of exchange in language use in a particular cultural context of certain inhabited populations, who use more than one language or language variety of intra- or inter-group aims (as cited in Garcia, 2009). Garcia notes that language maintenance and shifts always occur under particular conditions in society:

- When there is more than one language being in use in a society. 
- When there are status and language power difference that might cause a group to surrender their home language and adopt one that boasts off higher status.

- When there are economic problems, political issues or social pressure this causes one to adopt one language over another (Garcia, 2009).

\section{What this Means in Iraq}

A language's current condition tends to determine if it should be pertained or developed for future prospect. Horberger writes that the situation of Planning is directed at determining the functions of language in a community, like in the case where languages are named in a constitution as the official language of the country (nationalized). This kind of planning affects or influences the status of the language in the society, or how it stands, relative to other languages. In the case where the Arabic and Kurdish are the only two official languages named in the Iraqi constitution, their status is raised, while the statuses of other minority languages in the country are becoming marginalized. Therefore, language shift from minority languages to the dominant languages is more likely to take place as minority groups have the tendency to adopt the language with higher status.

In addition, it is evident that the use of languages in schools can lead to language maintenance, shift, and revitalization. While the constitution of Iraq shows and guarantees that children receive their education in their home language, we have seen reports indicating that many minority groups do not happen to have access to schools that teach in their language. According to Giles' (1977) framework, then, this lack of institutional support makes it easier for the language to become endangered. As pointed out, having bilingual schools that teach in both the home language of the child, and the dominant language in society will not find a paved path toward ensuring that the language will be revitalized.

Fishman and Giles both agree on the fact that the use of languages in government and employment can also lead to language maintenance, shift, or revitalization. A number of minority languages like Aramaic, and Turkmen had been excluded from government institutions, workplace speech and documents, while Arabic and Kurdish have their place in these domains. Additionally, the likelihood of the shift from minority languages to the dominant ones and the endangerment of minority languages is undeniably high. Finally, Giles pointed out that languages can be affected through regional distribution. We acknowledge how ethnic minority groups in Iraq have been forced to flee their communities in pursuit of an asylum. Some have been internally displaced while others found out solace in neighbouring countries. This is said to be the result of the fragmentation of speech communities, increasing the likelihood of language shifts to the dominant language. Fishman has noted that "Face to face, interaction with a real family embedded in real community is the real secret weapon of $R L S^{\prime \prime}$ (as cited in Garcia, 2009). If community members are segregated, the interaction needed for language revitalization will be close to impossible.

\section{Language Planning: Harmony in Bilingual Education}

Iraq is diverse linguistically; so the mono-glossic method to bilingualism would not be regarded as timely. This method holds firmly that a second language is improved separately from the first language. It ascribes to a monolingual ideology that children begin as monolinguals in one language and end up either monolingual in the second language or bilingual in the first and second languages (Garcia, 2009). An example of this type of method is a transitional program, aiming to facilitate the transition of the student from his or her home language to that of the dominant language. This should not be the target of Iraqi schools. What we should do instead is to encourage the students to maintain their home language(s) such as Aramaic or Turkmen and at the same time, develop competency in the dominant languages (Arabic or Kurdish).

In order to include minority languages in Iraqi education, a heteroglossic approach appears to be the most feasible approach. A heteroglossic model seeks to develop bilingualism while acknowledging that many children and communities are not strangers to bilingualism and diverse languages and they do not present themselves at school as monolinguals (Garcia, 2009). This approach recognizes the multiplicity of many speech communities, and seeks to boost the interaction and co-development of children from various linguistic backgrounds (Garcia, 2009). Under this type of approach, learning languages are not only a home agenda, but it is reinforced at school as well. They are based on the beliefs and practices of people who see languages as coexistent, not isolated from each other (Garcia, 2009). This model of bilingualism is confirmed to be appropriate in many communities in the linguistically diverse Iraq. Depending on the area in Iraq, minority children could be educated in their language and the dominant language (Arabic) with the help of a recursive or dynamic theoretical framework. The aim of this model is to activate the home language of a community that has all the while been suppressed. At this point, the child might. not be proficient in his/her ancestral language, but he or she is definitely not starting from scratch. However, in a recursive model, a child's ancestral language is not added as a whole but is developed in pieces and is reconstituted for new, modern functions (Garcia, 2009). This model may be appropriate in areas in Iraq, where there are cases of certain language repression, such as happening to the communities of the Turkmen.

An example of a type of bilingualism that adheres to the recursive model is immersion revitalization, occasionally referred as "heritage language immersion". Minority children who come from speech communities that have experienced language shift, or moving away from their ancestral language could also be taught this way. The goal is to reignite the functions and the situation of a language and reverse language shift. The point is not only to reclaim a heritage language that has undergone a language shift, but also to improve the curricula to combine the local knowledge 
and culture (Garcia, 2009). We have seen that the curriculum in many Iraqi schools tends to lean more towards the dominant groups.

\section{Conclusion, Solution and Recommendations}

The issue of bilingualism in the home and school in Iraq establishes steady challenges for educationists and relevant parties in Iraq. The study of language groups in Iraq justifies that despite the considerable difference in the language behaviour, all groups share the same value of the knowledge of Arabic, the common language used in the everyday communication as well as the official language used in the educational areas and other formal establishments. Simultaneously, all minority groups have expressed a strong desire for keeping and using their mother tongue. To cater for this desire, the education gate-keepers in Iraq had designed a modified legislation, law on 2005article (4) in 2009 where the law asserts that the educational system is to value not only majority languages but also minority languages such as Kurdish and Turkish.

In sum, the study suggests the recommendations below in order to instigate the education policy makers to improve and develop the bilingual education system in Iraq.

1. The Iraqi government should provide access to bilingual education for minorities in several areas that have a lot of minority groups. These schools should not be transitional in nature, or in other words, they should not pursue the ultimate goal of transitioning the child from their home language to the dominant language. Instead, these schools should advocate teaching in both the home language(s) of the student and the dominant language (either Arabic or Kurdish) and should ideally uphold either a recursive or a dynamic bilingualism model. 2. Review and revise school curricula all across the country to make them more representative of the minority groups' culture, history, and language. People representing ethnic minority groups should have very good involvement in the development of the curriculum.

3. Remove the requirement for minority teachers to work for three years outside their community. This way, they can be with their own people in their communities and teach in their language.

4. Provide Kurdish language training for linguistic minorities, especially in the northern part of Iraq.

5. Increase the number of minority representatives in the provincial councils so that minority groups can take part and have more voice in more language planning.

6. Collaborate with the minority to create a detailed anti-Discrimination law, and provide strong enough means of enforcement. This includes ruling out that language discrimination is one of the prohibited grounds of discrimination.

7. Eliminate the violence and intimidation faced by minority groups by creating a set of more stringent punishments for those who make the minorities their target. This will curtail further displacement and fragmentation of the latter.

8. Add 'Language' as one prominent ground for discrimination in the constitution (Article 4).

\section{References}

Al-Hirmizi, A. (2003). The Turkmen and Iraqi Home land. Kirkuk: KERKUKVAKFI. Retrieved from https://en.wikipedia.org/wiki/Iraqi_Turkmen

Center, E. H. (2001). Linguistic Diversity and Early Literacy: Serving Culturally Diverse Families in Early Head Start. Washington, DC: U.S. Department of Health and Human Services.

Roth, F. P., Speece, D. L., \& Cooper, D. H. (2002). A longitudinal analysis of the connection between oral language and early reading. The Journal of Educational Research, 95(5), 259-272.

Curran, M. E. (2003). Linguistic Diversity and Classroom Management. Ohio: College of Education.

Garcia, D. (2009). Bilingual Education in the 21st Century: A Global Perspective.

Giles, R. (1977). Perceived benefit model of language shift.

Harmers, J. F., \& Blanc M. H. A. (2004). Bilinguality and bilingualism (2nd ed.). Cambridge: Cambridge University Press.

Joshua Fishman, 1968. Language planning and language planning research: the state of the art.

Kerkuklu, M. S., \& Beyath, K. (2008). The Turkmen City of Tuz Khormatu. Iraqi Turks Society for Culture and Solidarity.

Mackey, W. (2000). The description of bilingualism. In L.Weir (Ed.), The bilingualism reader (pp. 22-50). New York: Routledge.

Macnamara, J. (1967). The bilingual's linguistic performance. Journal of Social Issues, 23, 58- 77.

Weir, L. (2000).Dimensions of bilingualism.InL. Wei (Ed.), The bilingualism reader (pp. 22-50).New York: Routledge.

Willems, G. M. (2002). Language Teacher Education Policy promoting Linguistic Diversity and Intercultural Communication. Strasbourg: DGIV.

Xing, H. (2003). Minority language planning of China in relation to use and development. Khadar, H. S. (2007).The legal status of Kurdish language in Iraq. Niqash: briefings from inside and across Iraq. Retrieved from http://www.niqash.org/articles/?id=2057 